\title{
Contracampo
}

\section{A cartilha da mulher adequada: ser piriguete e ser feminina no Esquadrão da Moda}

\section{The womens' guide to good manners:}

being dangerette and being feminine on Esquadrão da Moda

\section{Lígia Campos de Cerqueira Lana}

ligialana@gmail.com

Professora da Faculdade de Comunicação e Artes da PUC-Minas e doutora em Comunicação/UFMG.

Laura Guimarães Corrêa

quimaraes.laura@gmail.com

Professora adjunta do departamento de Comunicação Social da UFMG e doutora em Comunicação/UFMG.

Maitê Gugel Rosa

maitequqel@gmail.com

Bacharel em Comunicacão Social/UFMG.

Ao citar este artigo, utilize a seguinte referência bibliográfica

LANA, Lígia Campos de Cerqueira; CORRÊA, Laura Guimarães; ROSA, Maitê Gurgel. A cartilha da mulher adequada: ser piriguete e ser feminina no Esquadrão da Moda. In: Revista Contracampo, v. 24, n. 1, ed. julho, ano 2012. Niterói: Contracampo, 2012. Pags: 120-139.

\section{PPGCOM UFF}

\section{Edição 24/2012}

Ensaio temático "Sociabilidades em rede"

Contracampo

Niterói (RJ), v. 24, n. 1, jul./2012.

e-ISSN 2238-2577

A Revista Contracampo é uma revista eletrônica do Programa de PósGraduação em Comunicação da Universidade Federal Fluminense e tem como objetivo contribuir para a reflexão crítica em torno do campo midiático, atuando como espaço de circulação da pesquisa e do pensamento acadêmico. 


\section{Resumo}

Concordando com a proposição crítica de Angela McRobbie sobre o pós-feminismo, este artigo tem como objetivo refletir sobre o tratamento dedicado às mulheres no programa Esquadrão da Moda (SBT). No estudo de caso, comparamos duas personagens "transformadas pelo esquadrão", sob a perspectiva do "estar na moda" associado com a imposição de limites para a exibição do corpo feminino. As medidas da sensualidade e da feminilidade indicam que o corpo feminino deve sempre estar suscetível à adequação das regras do consumo, do trabalho e da felicidade individual, mesmo que às custas de humilhação.

Palavras-chave: pós-feminismo; moda; Esquadrão da Moda.

\section{Abstract}

In accordance with the critical position of Angela McRobbie about the post-feminism, this article aims to discuss how women are featured on the Brazilian TV show Esquadrão da Moda (SBT). We present a case study that compares two women who are "transformed by the squadron". The TV show associates the rules of "being fashionable" with the limits to display female bodies. The measures of sensuality and femininity indicate that the female body should always be susceptible to the rules of consumption, labor and individual happiness, even at the cost of humiliation. Keywords: post-feminism; fashion; esquadrão da Moda. 
$\mathrm{D}$ e acordo com Angela McRobbie (2004a), o pós-feminismo, estágio atual de enfraquecimento das lutas contra as desigualdades entre homens e mulheres, ocorre por meio de uma renovação baseada em um falso engajamento nas questões femininas. Ao contrário das "ondas" que caracterizam os momentos anteriores da problematização da experiência social feminina ${ }^{1}$, o feminismo contemporâneo enfrenta uma questão que apaga a legitimidade da própria reflexão sobre o tema. Ciente das conquistas alcançadas, a força do pós-feminismo reside em sua perspectiva aparentemente bem informada e bem intencionada com relação às desigualdades. A entrevista da apresentadora Sabrina Sato à revista Marie Claire em setembro de 2011 ilustra o argumento de Angela McRobbie.

Nunca liguei para essa coisa de ser considerada a gostosa burra. Sabe por quê? É meu personagem. Trocava frases e nomes das pessoas de propósito. Fiz tão bem que todo mundo acreditou. As feministas me criticam, como se eu, por me deixar zoar, mostrasse que os homens têm mais é que tratar mal as mulheres. Não penso assim. Errado, para mim, é tirar sarro de quem é inferior. E a gente deixou de ser há anos, ocupa os principais cargos do país. ${ }^{2}$ (grifos nossos)

A fala indica, por um lado, o conhecimento do que seriam as lutas pelos direitos das mulheres ("as feministas me criticam”), e, de outro, a divulgação de que as desigualdades foram superadas - "a gente (...) ocupa os principais cargos do país". Sabrina, a mulher pública bem-sucedida, alcançou reconhecimento enganando "todo mundo" a respeito de sua "burrice". Em sua posição de destaque, Sabrina divulga que as conquistas femininas estão ganhas e as desigualdades reivindicadas pelo feminismo estão superadas. A fala implica que Sabrina teve a liberdade de constituir um

\footnotetext{
${ }^{1}$ Apesar de o movimento feminista ser composto por distintas matrizes conceituais, a história das teorias feministas pode ser organizada em três ondas. A primeira onda do movimento feminista, ocorrida na passagem do século XIX ao XX, teve como principal reivindicação o sufrágio e outros direitos básicos da cidadania (Thébaud, 1991). Já a segunda onda, entre os anos 1960 e 1980, problematizou a liberdade sexual e o papel das mulheres no período pós-segunda guerra. O período pode ser compreendido a partir de duas entradas: as teorias anglo-americanas e as teorias francesas (Moi, 1985). A terceira onda do movimento, depois dos anos 1980, relaciona-se ao pós-estruturalismo e às teorias pós-colonialistas, em que a reflexão se volta às diferenças de classe e às matizes culturais de países fora do eixo norteamericano e europeu.

${ }^{2}$ CARUSO, Marina; LIMA, Camila. Prazer, Sabrina. In: Revista Marie Claire, setembro de 2011, no 246. São Paulo: Editora Globo, 2011, p. 79-83.
} 
personagem (burra ou esperta, não importa), que alcançou reconhecimento e prestígio em um contexto em que as mulheres possuem condições de igualdade para isso.

A revisão histórica de momentos recentes das pesquisas feministas, especialmente no campo dos estudos culturais, mostra que os anos 1990 trazem a reflexão sobre o movimento, um tempo de balanço, que resgata uma ideia de "sucesso feminino" (McRobbie, 2004a). Ao mesmo tempo, a circulação na mídia e em outras instituições de valores ligados às conquistas femininas caminha junto com a rejeição ao feminismo. "Parece que, para ser uma jovem hoje, é necessário este tipo de denúncia ritualística que sugere que o desempoderamento do feminismo é uma estratégia que o inclui no passado e o marca como pertencente a outra geração, logo, está ultrapassado."3 (McRobbie, 2004a: 258). A declaração de Sabrina Sato confirma esse recente passado histórico: "as feministas" seriam pessoas críticas e estranhas a elas mesmas, pertencentes a outros mundos e contextos. ${ }^{4}$

$\mathrm{Na}$ articulação com esse arrefecimento, McRobbie traz o conceito de individualismo para Anthony Giddens, Beck e Beck-Gernsheim e Zygmunt Bauman. A modernização social, vista sob essa perspectiva, concede aos indivíduos a responsabilidade pelas determinações de suas vidas. Dessa maneira, apagando as desigualdades históricas entre homens e mulheres, o individualismo moderno faria com que as escolhas reflexivas da vida feminina, desde a escolha de um bom marido até as opções de carreiras profissionais, sejam vistas como determinações individuais, desconectadas (ou "desmembradas") de relações de poder que formatam as normas de gênero.

O contexto do pós-feminismo introduz a problemática de nosso objeto de estudo, o programa Esquadrão da Moda, exibido pelo SBT. As candidatas à transformação do visual - argumento em torno do qual a narrativa do programa se estrutura - são mulheres; dentre as 108 edições citadas no site do Esquadrão da Moda, apenas em uma o candidato é um homem. Isabella Fiorentino e Arlindo Grund,

\footnotetext{
3 "To count as a girl today appears to require this kind of ritualistic denunciation, which in turn suggests that one strategy in the disempowering of feminism includes it being historicised and generationalised and thus easily rendered out of date." (tradução das autoras)

${ }^{4}$ Julia Kristeva (1988) trabalha com o conceito de estrangeiro ao discutir a posição das mulheres na cultura e na literatura. "Estrangeiras a si mesmas", a constituição das desigualdades faz com que as mulheres não se reconheçam como integrantes legítimas do lugar em que vivem. A autora traz o exemplo das Danaïdes, personagens mitológicas que, morando em um país como forasteiras, tornam-se estranhas ao seu próprio lar quando matam seus maridos(Kristeva, 1998).
} 
especialistas-apresentadores de Esquadrão da Moda, ensinam para "mulheres consideradas sem estilo ou que simplesmente se vestem de forma inadequada (...) como se vestir bem e com estilo". As "vítimas" do programa devem se tornar adequadas aos mais diferentes parâmetros - as regras de se vestir bem são associadas às normas da beleza, do comportamento e da autoestima. Esquadrão da Moda, quando não convida homens para a transformação do visual, dialoga com o ponto de vista de Angela McRobbie. No contexto do pós-feminismo, há o enfraquecimento das possibilidades de questionar a desigualdade de condições entre homens e mulheres. A exclusividade da participação feminina ocorre de maneira silenciosa, como se fosse natural que mulheres necessitem mais de orientação para a adequação às normas sociais.

Em outro trabalho, publicado em uma edição especial da revista The Sociological Review dedicada ao tema "feminismo depois de Pierre Bourdieu", Angela McRobbie (2004b) propõe uma análise do programa What Not To Wear, versão inglesa que deu origem ao Esquadrão da Moda. McRobbie afirma que as mulheres sofrem "violência simbólica", pois são desvalorizadas publicamente por especialistas e apresentadoras em razão de supostamente terem pouco ou nenhum gosto estético. Em What Not To Wear, há "claros elementos de classe" relacionados à dinâmica da humilhação das participantes inglesas, oriundas das classes trabalhadoras. "Na base de seu habitus de classe subordinada, (...) ela vai instintivamente e inconscientemente saber seu lugar ao ser analisada pelos especialistas, por isso as lágrimas, a gratidão e a deferência por aqueles que têm mais conhecimento que ela." (McRobbie, 2004b:103). O programa pretende realizar uma transformação no habitus das classes trabalhadores causando a vergonha e, em seguida, ensinando e instruindo corretamente seus modos de vestir no ambiente de glamour da televisão.

O trabalho de Angela McRobbie, apesar de publicado há alguns anos, aponta conclusões que podemos observar contemporaneamente no Esquadrão da Moda. Conforme nossa análise preliminar, as participantes brasileiras também são integrantes das classes trabalhadoras. Nos programas que analisamos, os conselhos sobre a roupa

\footnotetext{
${ }^{5}$ http://www.sbt.com.br/esquadraodamoda/oprograma/. [inserir última data de acesso]

6 "On the basis of her own subordinate class habitus, the individual will have a 'feel for the game', a 'practical sense for social reality' which means that in the context of the programmes she will instinctively, and unconsciously, know her place in regard to the experts, hence the tears, the gratitude and the deference to those who know so much better than she does, and who are willing (temporarily) to share this knowledge and expertise." (tradução das autoras)
} 
adequada para a correta inserção no mercado de trabalho são recorrentes. Além disso, outros elementos narrativos que caracterizam as participantes, como o bairro em que vivem, os lugares que frequentam e o emprego que possuem ou almejam, sinalizam que se trata de mulheres oriundas da classe média baixa ${ }^{7}$. Para McRobbie, a pressão para a adequação das classes trabalhadoras ressalta o principal indício da violência simbólica atrelada às questões de classe.

Que tipo de menina é esta? Não está vestida para trabalhar, portanto não está ganhando a vida honestamente. Mas não é estudante. (...) Os corpos das jovens mulheres devem agora ser entendidos de acordo com a escala para a busca de benefícios do governo (...) A garota "pramface", encrencada e malvestida, usando roupas baratas e comuns, com uma criança no carrinho, contrasta exatamente com as garotas "A1", que têm renda para investir em si mesmas e aspiram a participação plena na cultura do consumo. (McRobbie, 2004b: 102). ${ }^{8}$

Nossa proposta ao analisar o programa Esquadrão da Moda traz as questões relacionadas à inserção das participantes no mercado do trabalho - e, como argumenta McRobbie, no universo do consumo - problematizando a maneira como a adequação do vestuário constitui um corpo brasileiro feminino que pode ser mostrado ou escondido por meio das roupas escolhidas. A questão que lançamos para o estudo dos casos busca associar os sentidos do "estar na moda" à conformação de limites para a exibição do corpo feminino. $\mathrm{O}$ ambiente de trabalho demanda roupas que não sejam sensuais; os valores associados ao universo laboral implicam elegância, discrição, simpatia e bomtom $^{9}$. Ao mesmo tempo, a mulher brasileira é comumente associada à sensualidade. $\mathrm{O}$

\footnotetext{
${ }^{7}$ Jesse Souza (2010) propõe a reflexão sobre os conceitos "nova classe média" e "classe trabalhadora" no Brasil contemporâneo. Segundo o autor, apesar de índices econômicos indicarem o aumento da renda de classes baixas, o florescimento de uma "nova classe média" depende de fatores culturais e simbólicos. A "nova classe média" é, ao contrário, uma "classe trabalhadora", que dedica grande parte de seu tempo ao trabalho em busca da inserção no universo do consumo - eles são aqueles que alavancaram o crescimento econômico brasileiro nos últimos anos.

8 "What kind of girl? Not dressed for work, therefore not earning an honest living. But not a student. (...) The bodies of young women are now to be understood according to a scale running from welfaredependent (...) The pramface girl who is pinched and poor-looking, common and cheaply dressed, with a child in a buggy, is in sharp contrast to the 'A1' girls who can spend a disposable income on themselves and aspire to full participation in consumer culture." (tradução das autoras).

9 Erving Goffman (2009) analisa as posturas femininas no universo de trabalho, mostrando que as desigualdades entre os gêneros podem ser observadas em gestos cotidianos dos tipos de cargos ocupados
} 
clima tropical interfere nas escolhas de roupas que deixam o corpo à mostra, se comparado aos países europeus ou aos Estados Unidos. O Esquadrão da Moda no Brasil, ao ser adaptado da versão da BBC What Not to Wear, colore com valores locais a violência simbólica sofrida pelas participantes. Nosso trabalho investiga como o programa elege roupas que "estão na moda" dentro dos padrões daquilo que seria aceitável para a sensualidade correta da mulher brasileira.

\section{Estar na moda}

A moda pode ser entendida como um conjunto de opiniões, gostos e apreciações críticas, bem como modos de agir, viver e sentir coletivos, aceitos por determinado grupo humano num dado momento histórico. De acordo com Barthes (2005), a tendência de toda cobertura corporal é a de se inserir em um sistema formal organizado, normativo, consagrado pela sociedade.

É, portanto, expressamente em nome do social que o vestuário deve ser descrito, e não em termos de formas estéticas ou de motivações psicológicas, mas em termos de instituição; o historiador e o sociólogo não têm de estudar apenas gostos, modas ou comodidades; precisam recensear, coordenar e explicar regras de disposição ou uso, imposições e proibições, tolerâncias e transgressões; não devem recensear "imagens" ou traços consuetudinários, mas relações e valores; essa é a condição preliminar de toda relação entre vestuário e história, pois precisamente essas correlações normativas são, em última instância, veículos de significação. (Barthes, 2005: 266).

A moda é uma instituição definida por normas que proíbem ou toleram, regulando os corpos e aquilo que se veste sobre eles. Há normas, sutis ou não, que perpassam nossa cultura e são concretizadas nas práticas e nos discursos diversos que se nos apresentam. A norma pode ser entendida como o que se deve fazer. No caso das normas da moda, determina-se o que, quando e como se deve vestir. Esses sistemas reguladores são sustentados e garantidos por sanções sociais. Lembramos aqui o que já escrevia Lévi-Strauss (2003: 12) em 1950: “(...) cada sociedade impõe ao indivíduo um uso rigorosamente determinado de seu corpo".

pelas mulheres. Entre outros aspectos, ele mostra que, geralmente, as mulheres são associadas a profissões que exigem o cuidado e a simpatia diante dos interlocutores, como secretárias, comissárias de bordo e enfermeiras. 
Para analisar a moda de um tempo, é preciso vê-la com algum estranhamento. O que se usa hoje não se usava ontem e não se usará amanhã. Há releituras e revivals, mas a moda de uma época nunca se repete totalmente. A moda também muda de acordo com o espaço: o que se veste aqui pode não ser usado em outros lugares. Assim como a adequação do vestuário, o julgamento estético é mutante. O belo é constituído pela época, com sua moral, seus valores, suas aspirações. $\mathrm{O}$ uso - e sua proibição ou aceitação - de peças de vestuário está inserido nas culturas e reflete seus valores vigentes. Historicamente, o vestuário feminino tem estado no centro de discussões políticas que vão muito além do gosto.

Sobre o corpo feminino há importantes embates de poder; nele estão inscritas as marcas da cultura. Há moda também para os corpos, principalmente para os corpos das mulheres, que, por uma histórica dominação de gênero, sofrem maior regulação e estão sujeitos a uma maior exposição. Podemos citar peças emblemáticas e carregadas de significado como burcas, véus, biquínis, sutiãs etc., que já foram e ainda são objeto de leis, reivindicações, manifestações.

A fala dos especialistas do programa Esquadrão da Moda revela e reforça normas atuais para o corpo feminino, seja quando elogiam a beleza do corpo de uma participante, seja quando dizem que algumas partes de seu corpo devem ser disfarçadas ou escondidas. O termo "esquadrão" está relacionado ao universo semântico bélico e militar. Pode significar um "grupamento de navios de guerra" ou uma "seção de um regimento de cavalaria" (Houaiss e Villar, 2001: 1239). A escolha dessa palavra para a expressão que dá nome ao programa não é aleatória. O reality show em questão, encarnado em seus apresentadores especialistas e profissionais da beleza, coloca-se como um pequeno exército que combate, com violência simbólica, as formas inadequadas do vestir, assim como tudo aquilo que é considerado fora de moda. $\mathrm{O}$ nome do programa se assemelha ainda à expressão "esquadrão da morte", que se refere a grupos de extermínio, geralmente para-policiais, que se caracterizam pelo uso ilegal da violência no suposto combate à criminalidade.

No programa, as normas são apresentadas de forma bastante inequívoca. Isabella e Arlindo, apresentadores-especialistas, são autoritários, irônicos, desrespeitosos, imperativos. Eles utilizam uma forma de humor agressiva, de modo a envergonhar e causar constrangimento. Os itens do guarda-roupa da participante são literalmente 
atirados ao lixo. Recolhemos, em alguns programas, os termos usados pelos especialistas, que desqualificam as participantes-vítimas e suas escolhas de vestuário: “cafona, feio, horror, medonho, horrível, ridículo, bobinho, careta, vulgar, escandalosa, inadequada, equivocada". Essas palavras se opõem àquelas dirigidas à participante no momento final da transformação, em que ela se torna "clássica, sóbria, nobre, elegante, chique, antenada, nova, moderna, sofisticada".

Essa solução transformadora (à la Cinderela) apresentada pelo programa está em consonância com o pensamento contemporâneo que valoriza o individualismo, a capacidade - e até o dever - de cada pessoa construir para si uma imagem de eficiência, sucesso, adequação e felicidade. Nessa auto-modelação, vista como expressão de uma personalidade única, a pessoa pode parecer o que quiser por meio do vestuário: romântica, jovem, divertida, rebelde, sexy, esportiva e tantos outros adjetivos que ouvimos nos discursos publicitários. A moda, com suas normas rígidas e, ao mesmo tempo, contando com uma indústria poderosa e diversificada, é instituição fundamental para essa construção do indivíduo contemporâneo, sempre "antenado" e "up to date". Como afirma Kellner, "moda e modernidade aliam-se para produzir personalidades modernas à cata de identidade em constantes renovações e atualizações de roupas, aparências, atitudes e estilos, com medo de estar desatualizadas e fora de moda" (Kellner, 2001: 337). A moda e sua publicidade vendem como valores a personalidade, o estilo próprio e a autenticidade, mas, a cada estação, muda-se o que é considerado normativamente um must ou aquilo que está out. Os indivíduos têm a liberdade vigiada de escolher roupas, estilos e imagens por meio dos quais produzirão suas próprias identidades, cada vez mais efêmeras e cambiantes. A rotatividade e a frivolidade características da moda alimentam a dinâmica de consumo acelerado.

Nesse processo, fortalecem-se os apelos e as motivações individuais e individualistas, sugerindo que os indivíduos conquistem uma suposta autonomia por meio do consumo de moda. A "mudança de visual" é procurada não só pelo desejo de ostentação e de diferenciação, como em Veblen (1965), mas também pela busca de uma metamorfose de si. Acredita-se - e é isso que o Esquadrão da Moda vende - que modificar a imagem por meio de roupas, maquiagem, corte de cabelo são formas de fazer com que a mulher-vítima esteja bem consigo mesma e com os grupos a que pertence. 


\section{A estrutura do programa Esquadrão da Moda}

O Esquadrão da Moda é o primeiro reality show exibido no Brasil que tem como foco a transformação por meio das roupas. No entanto, a temática mais ampla de transformação do visual não é inédita na programação brasileira. Desde o final dos anos 1990, esse tipo de abordagem aparece em quadros como Dia de princesa, do Domingo da Gente (Rede Record), e Transformação, do Planeta Xuxa (Rede Globo). Ao longo dos anos 2000, quadros similares, como o Beleza Renovada, no Eliana (SBT) foram criados. Em linhas gerais, esses programas trazem mulheres para a transformação de sua aparência, recebendo algum tipo de recompensa por sua participação. Durante o processo de mudança, o programa busca ensinar essas mulheres a serem mais bonitas e a elevar a autoestima, fazendo as escolhas certas, percebendo a vida por determinada ótica. Os canais pagos também apesentam esses quadros, alguns produzidos em outros países, como aqueles exibidos no Discovery Home \& Health (What Not to Wear, How Do I Look, 10 Anos Mais Jovem), ou no Brasil, como no GNT (Plástica Perfeita e Superbonita Transforma).

O Esquadrão da Moda foi exibido durante dois anos pelo SBT, com periodicidade semanal (não houve um dia fixo para transmissão), no período noturno, entre 20h e 21h. O Esquadrão da Moda ficou fora do ar durante o ano de 2011, retornando à grade de programação do SBT em abril de $2012^{10}$. Os apresentadores são especialistas que ensinam de forma didática qual é o caminho para cultivar uma boa aparência e, por consequência, a autoestima. A modelo Isabella Fiorentino e o stylist Arlindo Grund ${ }^{11}$ são responsáveis pela condução dos elementos narrativos do programa. Eles apresentam o problema a ser solucionado, ensinam as regras da moda e julgam a transformação da participante. Além dos dois, o programa também traz o cabeleireiro Rodrigo Cintra e a maquiadora Vanessa Rozan, que transformam o cabelo e a aparência facial das participantes.

\footnotetext{
10 Conforme notícia veiculada no site do programa (http://www.sbt.com.br/esquadraodamoda/noticias/?id=9724) em 26 de março de 2012.

${ }^{11}$ Desde novembro de 2011, Arlindo Grund apresenta o Tenha Estilo (SBT), um programa diário com duração de cinco minutos que divulga orientações de moda (http://www.sbt.com.br/tenhaestilo/).
} 
Acompanhando o formato original da BBC, a cada semana o programa traz uma participante diferente, que passa pela transformação de sua imagem. As participantes são denominadas "vítimas", assim como em What Not to Wear. De maneira geral, podese dizer que o roteiro busca convencer as participantes que elas estão infringindo normas de conduta e padrões de gosto relacionados com a construção de sua aparência e imagem pessoal. Outro foco do roteiro é persuadir as participantes a se submeter à transformação. Três etapas podem ser identificadas na narrativa, nesta ordem: vergonha, aprendizagem e mudança.

$\mathrm{Na}$ fase da vergonha, a mulher é submetida a uma sessão de críticas protagonizada pelos apresentadores, amigos/as e familiares. Imagens da participante gravadas secretamente buscam comprovar os problemas apontados. O convite para participar do Esquadrão da Moda geralmente acontece em locais públicos, quando os apresentadores fazem a oferta de um cartão que dá direito a 10 mil reais em roupas novas sob a condição de a participante entregar todas as peças de seu guarda-roupa. Denominada "terapia de choque", a primeira etapa da narrativa ocorre em frente a um espelho de $360^{\circ}$, onde a participante é convidada a se olhar por todos os ângulos em uma cabine retangular com espelhos em todas as suas paredes internas. A vítima veste suas roupas e explica o motivo pelo qual gosta daqueles trajes. Arlindo e Isabella entram na cabine e criticam peça por peça. Em seguida, no estúdio do programa, composto basicamente por araras cheias de roupas da participante e uma grande lixeira em primeiro plano, os apresentadores jogam fora todas as peças. A lixeira tem um significado muito forte, já que é o destino de tudo que a vítima usava antes de passar pela transformação.

$\mathrm{Na}$ fase de aprendizagem, a participante aprende tanto o que não deve usar quanto o que é adequado. Essa etapa retoma os elementos da primeira fase para ensinar aquilo que está errado. A mulher aprende o que é certo por meio das sugestões apresentadas [sugestão: trocar "apresentadas" por "dadas" para evitar repetição] pelos apresentadores. As composições de vestuário são apresentadas de maneira didática, sempre evidenciando por que as peças são adequadas para a participante. Depois de passar pelas aulas de estilo, a participante vai às compras. Em lojas previamente escolhidas por Arlindo e Isabella, a participante tem dois dias para escolher as peças e acessórios que irão compor o seu novo guarda-roupa. No primeiro dia ela vai às 
compras sozinha. Já no segundo dia, a participante é surpreendida pelos apresentadores, que acompanham e orientam as compras para garantir que algumas peças fundamentais sejam adquiridas.

A narrativa é finalizada com a transformação, que parece solucionar os problemas apontados na primeira etapa. A mudança na imagem sugere uma consequente mudança de atitude e de estado de espírito, que pode ser maior autoconfiança, elevação da autoestima ou felicidade. No salão de beleza, o processo de transformação se completa com uma consultoria de cabelo e maquiagem. Com guarda-roupa renovado, cabelo novo e maquiagem feita, a participante desfila para Arlindo e Isabella que, impressionados com as mudanças, elogiam e aplaudem a transformação na aparência. Enquanto a participante faz poses para a câmera e se admira no espelho, a narração descreve as peças utilizadas e informa os preços. O programa se encerra com o depoimento da participante transformada, que fala sobre a experiência de participar do Esquadrão da Moda e agradece emocionada pelas consultorias.

Em nossa pesquisa, analisamos seis edições recolhidas ao longo de um ano, entre dezembro de 2009 e novembro de 2010. Na etapa de coleta de material, buscamos os programas exibidos na primeira semana de cada bimestre (01/12/2009, 02/02/2010, 07/04/2010, 02/06/2010, 03/08/2010 e 05/10/2010) ${ }^{12}$. Em uma análise preliminar, as conclusões indicaram a adequação das mulheres ao universo do trabalho, dialogando e trazendo aspectos empíricos às observações de Angela McRobbie a respeito de What Not to Wear. Depois de finalizar a pesquisa dos seis programas, realizamos uma nova leitura do material, buscando estabelecer correlações com a problemática do pósfeminismo e com a adequação das mulheres sob a perspectiva de normas que trazem os limites para a sensualidade feminina. Nessa segunda análise do material, duas edições nos pareceram exemplares para a problematização dos conceitos de Angela McRobbie e do sentido normativo da moda. Apresentamos a seguir a leitura desses dois casos, que, de maneira comparativa, trazem as tensões com relação à nossa problemática ${ }^{13}$.

\footnotetext{
${ }^{12}$ A primeira fase da pesquisa foi realizada pela estudante de iniciação científica Maitê Gugel Rosa (Probic/CNPq), sob orientação da profa. Dra. Vera Veiga França e da profa. Dra. Lígia Campos de Cerqueira Lana. A monografia está disponível na biblioteca on-line do GRIS, Grupo de Pesquisa em Imagem e Sociabilidade da UFMG (http://www2.fafich.ufmg.br/gris/index.php/biblioteca/monografias).

${ }^{13}$ Os programas analisados neste artigo podem ser acessados no site Youtube, conforme referências indicadas ao final do texto.
} 


\section{A mulher perigosa}

Melissa Stoner, personagem do programa exibido em 7 de abril de 2010, tem 22 anos e usa roupas justas, curtas e decotadas, deixando partes do corpo à mostra. $\mathrm{O}$ estilo de Melissa é considerado vulgar por seu namorado, suas amigas e seus parentes. A participante foi indicada pelo namorado para participar do programa. Ele se diz constrangido pela forma como Melissa se veste, já que ela chama a atenção de outros homens. "Você sente ciúmes ou orgulho de ver a sua namorada assim?", Arlindo pergunta, no programa. "Nenhum dos dois. Eu me sinto superenvergonhado", afirma o rapaz, que define: "o estilo da Melissa é largado, é estilo 'piriguete"”. No programa, por várias vezes o namorado é citado como aquele que vai aprovar (ou não) a transformação de Melissa. O especialista intervém: "eu estava esperando isso: é totalmente 'piriguete"'. Dirigindo-se à participante, Arlindo explica: "essas suas roupinhas são um atentado à segurança nacional. Se você continuar andando assim vai precisar andar com vários seguranças em volta, porque se não, não dá”. $O$ comentário do especialista sugere, em tom jocoso e ameaçador, que Melissa pode ser atacada (sexualmente?) por causa da roupa que usa.

Melissa, frequentadora assídua de bailes funk e pagodes, diz se sentir bem se vestindo dessa forma. Ela avisa aos especialistas que seus gostos e convicções não serão modificados tão facilmente. Enquanto os apresentadores criticam e jogam no lixo as roupas da participante, ela diz que ama aquelas peças.

No desfile final, a transformação de Melissa parece ter agradado mais aos especialistas do que à própria participante. Arlindo e Isabella avaliaram que seu estilo se manteve sexy, mas sem vulgaridade. Melissa não se mostrou tão contente. Ao final da transformação, ela afirma: "adorei, não tenho do que reclamar. Parece outra pessoa". Isabella reclama que ela "ainda não me convenceu muito que está soltando fogos de artifício de alegria". 


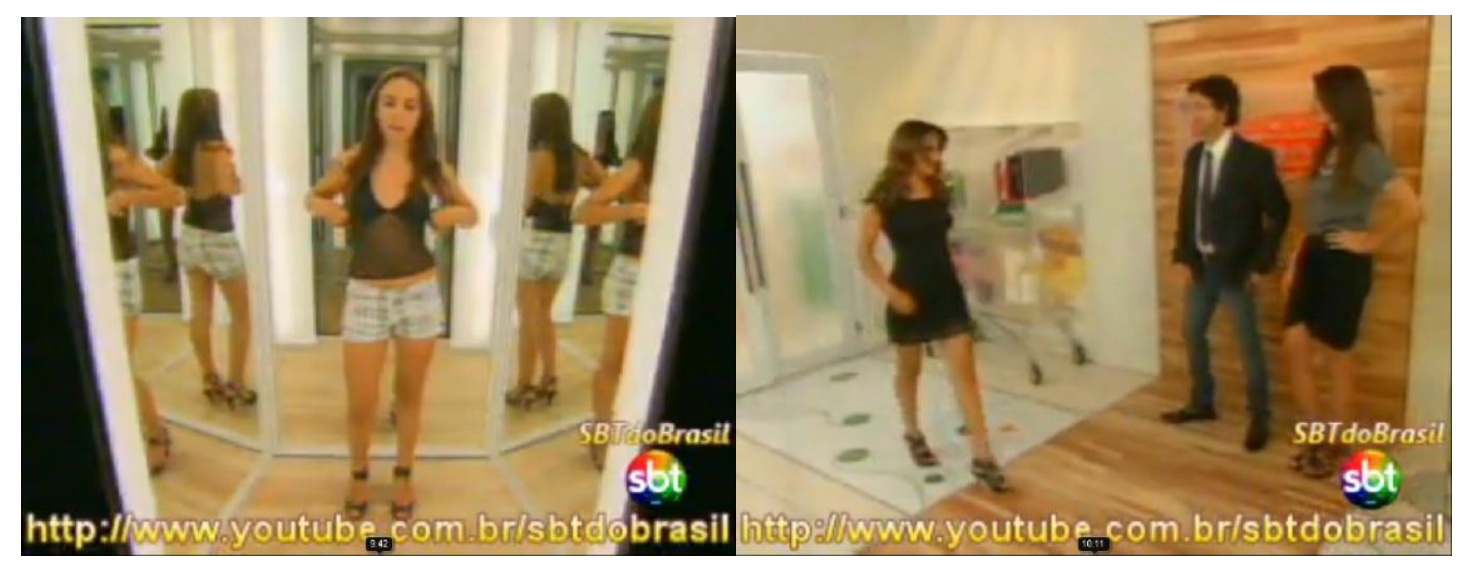

Fonte: Canal SBT no Youtube. As imagens mostram a transformação de Melissa.

Melissa tem um namoro estável e se mostra comprometida com o namorado, mas afirma o desejo de ser notada por outros homens. O programa deixa claro que isso é uma infração, estabelecendo os limites entre o aceitável e o inaceitável.

A escolha pelo uso de roupas curtas e justas faz com que as pessoas definam o estilo da participante como "piriguete". O termo piriguete (ou periguete), de conotação pejorativa, tem sido usado (na música popular, na mídia, na conversa informal) para definir a mulher que não está adequada aos padrões tradicionais de conduta feminina, seja por ter muitos parceiros sexuais, seja por agir ou se vestir de maneira considerada provocante. A mulher piriguete é vista como um perigo para a sociedade, pois ameaça valores tradicionais com seu comportamento sexual fora de relações estáveis/aceitas ou pela exposição do corpo, que pode sugerir conduta inadequada ${ }^{14}$. É importante observar que não há termo pejorativo correspondente que se refira ao comportamento sexual heterossexual masculino ou à maneira de se vestir do homem. A crítica ao homem passa pela heterossexualidade/homossexualidade. Chamar a atenção do sexo oposto ou se relacionar com muitas mulheres não é considerado um problema para os homens, pelo contrário, é algo valorizado socialmente.

\footnotetext{
${ }^{14}$ A matéria "Maria e a Revolução da "periguete"”, de Nina Lemos, apresenta significados para a palavra "periguete" e uma reflexão sobre como julgar alguém [trecho não está claro]: http://www1.folha.uol.com.br/ilustrada/894883-nina-lemos-maria-e-a-revolucao-da-periguete.shtml . [incluir última data de acesso] O tema foi explorado também pela revista TPM, em reportagem assinada pela mesma jornalista: http://revistatpm.uol.com.br/reportagens/sera-que-voce-e-piriguete.html. [incluir última data de acesso]
} 
Apesar de apresentar uma estrutura bastante fechada e previsível, a edição do programa que mostra a transformação de Melissa não parece ter sido muito bemsucedida. A participante, em momento algum, aceita passivamente o lugar da vítima: não se envergonha da sua maneira de vestir, nem se mostra completamente satisfeita com a solução operada pelo programa. Ao que parece, a norma de exposição do corpo, imposta pelos especialistas da moda, continuará a ser transgredida pela participante, que não se importa em ser chamada de piriguete. De qualquer forma, os discursos apresentados no programa deixam claras para o público as regras do vestir feminino.

\section{A mulher menino}

Thabata Alves, personagem do Esquadrão da Moda em 5 de outubro de 2010, tem 19 anos e usa roupas largas e confortáveis, principalmente moletons e tênis. As amigas, familiares e colegas de trabalho consideram seu estilo infantil e inadequado para a exposição em ambientes públicos. Ela foi indicada pelo namorado, que diz: "o que mais me incomoda é a roupa estilo de homem, que é muito largada, não está tão na moda". Os apresentadores e as pessoas entrevistadas afirmam que Thabata é pouco feminina. A participante diz se sentir bem com as roupas que veste. Ela é fã de futebol, esporte tradicionalmente masculino. No programa, salienta-se que ela precisa manter a feminilidade para que possa torcer pelo seu time sem parecer um "homenzinho".

Os apresentadores sugerem peças mais delicadas, que deixem a participante mais feminina: "a gente sabe que você não gosta muito de sandália alta, mas é importante uma mulher estar de sandália alta", diz Arlindo. "Você tem um corpo perfeito. A gente não precisa disfarçar barriguinha, bumbum grande, seio grande, nada.", explica Isabella. "Você estava escondida naquele cabelão lambido, com aqueles moletons gigantescos. Olha que corpinho lindo que você está", diz Isabella. "E aqueles moletons pareciam mais uma barraca de camping, onde você se escondia literalmente dentro.", aponta Arlindo. O cabeleireiro faz algumas luzes claras e desfia o cabelo de Thabata para deixá-la mais "mulherão". 


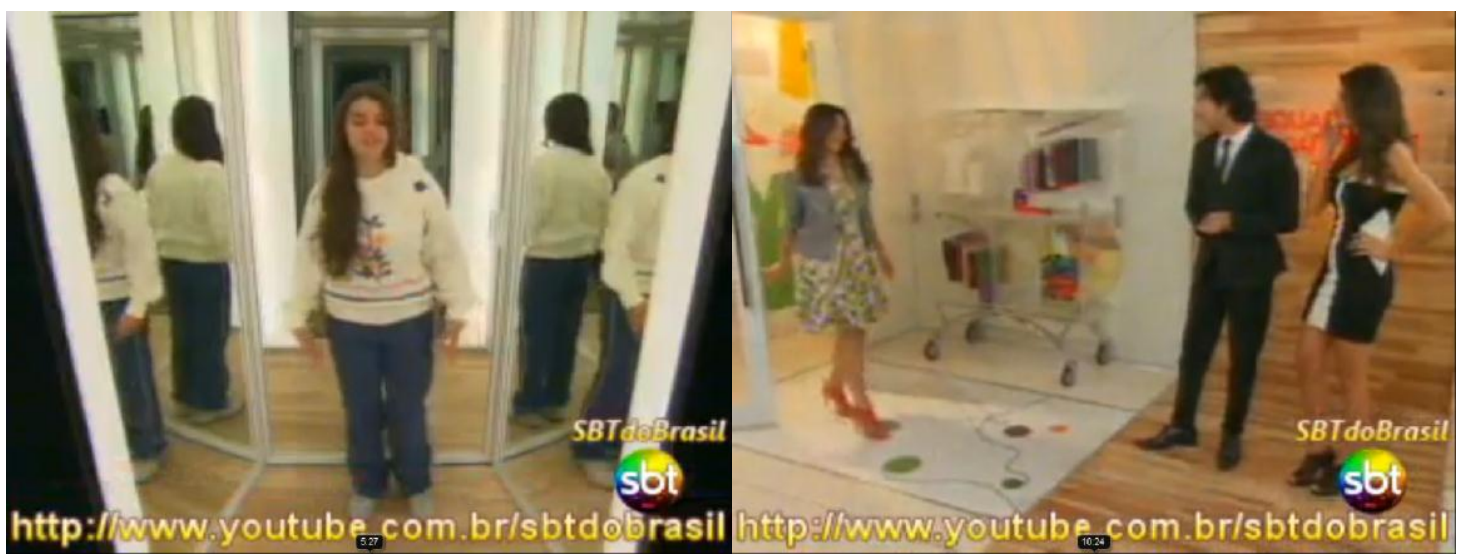

Fonte: Canal SBT no Youtube. As imagens mostram a transformação de Thabata

Por fim, os especialistas resolvem o último "problema", presenteando Thabata com um conjunto feminino do Corinthians com calça, camisa baby look e jaqueta, todos de modelagem mais justa. A participante se mostra felicíssima com a surpresa e avalia positivamente a transformação. A cena final, em clima romântico clichê, mostra a participante no colo do namorado, recebendo dele uma flor, símbolo da feminilidade.

A edição do Esquadrão da Moda que apresenta Thabata opera em sentido oposto àquela edição do programa que tenta transformar Melissa. Se esta infringia as normas ao expor o corpo, Thabata é infratora por manter as formas de seu corpo protegidas dos olhares das pessoas, sendo considerada pouco feminina por isso. É como se a feminilidade devesse ser provada através de uma oferta visual (mas apenas das partes permitidas) do corpo feminino. Depreende-se desse contraste que há um controle rigoroso do equilíbrio entre o que se esconde e o que se mostra por meio do vestir.

\section{Conclusão}

No programa Esquadrão da Moda, o corpo da mulher (e o que ele veste) é passível de críticas e regulações. Evidencia-se a existência de normas claras para a exposição pública - e até privada - do corpo feminino. Argumentos estéticos mascaram uma condição de desigualdade para a constituição da aparência entre gêneros, oferecendo normas de comportamento. As atitudes transgressoras quanto ao vestuário podem desestabilizar determinadas relações de poder entre homens e mulheres. Nos casos de Melissa e de Thabata, ficam evidentes as sanções a quem não se adapta aos 
padrões vigentes, infringindo as normas que regulam o gosto em determinada época e lugar.

O Esquadrão da Moda apresenta o problema: Melissa gosta de mostrar o corpo, mas o namorado não gosta dessa exposição. Thabata gosta de se vestir confortavelmente, mas o namorado acha seu estilo pouco feminino. O Esquadrão da Moda combate ao lado deles e aparentemente oferece a solução para esses conflitos através do constrangimento, da humilhação e da oferta de um novo guarda-roupa, ensinando e instruindo essas jovens para que se tornem mulheres adequadas - para seu homem e para seu trabalho. Os namorados de Melissa e Thabata têm o mesmo ponto de vista do programa com relação às regras corretas para a exposição do corpo feminino; as orientações do Esquadrão da Moda legitimam-se junto com os posicionamentos masculinos.

Tanto a estrutura do Esquadrão da Moda quanto as falas e imagens apresentadas pelo programa reforçam a ideia de que o corpo feminino é algo a ser regulado, controlado. Essa regulação é personificada pelos especialistas que apresentam o programa. Nos dois casos analisados, o "cúmplice" do esquadrão é o namorado da "vítima". Com demandas opostas, os parceiros dessas mulheres buscam a medida certa da exposição dos corpos. Segundo as prescrições do programa, as roupas não devem esconder as formas do corpo a ponto de fazer com que a mulher pareça masculina ou infantil, apagando sua feminilidade. Por outro lado, as roupas devem cobrir o corpo feminino para que não mostre tanto a ponto de parecer disponível aos outros homens. Assim, os discursos apontam para uma valorização de uma suposta sensualidade/sexualidade feminina no vestir, desde que contida.

O esquadrão não se propõe a combater possíveis inadequações do vestuário masculino. No universo masculino heterossexual, o esmero no vestir pode ser considerado falta de virilidade. Essa diferença pode ser lida como uma relativa liberação dos homens da moda - um assunto tido como fútil, algo do universo feminino ou gay. Pode-se ler essa diferença também como mais uma marca do desequilíbrio de poder entre gêneros, numa concepção na qual a aparência da mulher é ainda considerada o fator mais importante para seu sucesso, aceitação e felicidade.

O programa televisivo opera uma transformação que se dá principalmente por meio do consumo. A norma, para estar na moda, é gastar dinheiro mais frequentemente, 
com roupas melhores e mais caras, dada a dinâmica dessa indústria sustentada pelo sistema simbólico que valoriza a substituição constante de itens desejáveis e admiráveis. $\mathrm{Na}$ análise dos programas, observa-se a imposição de valores de uma classe (mais alta) para outra (mais baixa). É certamente mais fácil ser elegante - dentro dos padrões vigentes - quando se dispõe de tempo e dinheiro para comprar nas lojas escolhidas pelo Esquadrão da Moda: adquirem-se ali, sob a assistência de vendedoras treinadas e que dominam os códigos do "bom gosto", produtos mais caros que os populares, mais bem desenhados, com materiais melhores etc.

A cultura contemporânea trata a felicidade e o bem-estar como um direito e um dever do indivíduo. Esse é também um dos pontos explorados pelo programa: a aparência e, consequentemente, a moda, é dos caminhos para a conquista dessa felicidade individualista. Vestindo-se bem, essa mulher transformada pelos especialistas pode conseguir um namorado, um emprego, a admiração das pessoas etc. $\mathrm{O}$ programa defende a possibilidade de transformação de si através da moda. Como confirma Thabata ao fim do programa: "Agora eu sou uma nova pessoa. (...) Mudei muito, assim, agora acho que realmente sou uma mulher."

\section{Referências bibliográficas}

BARTHES, Roland. Inéditos Vol. 3 - Imagem e Moda. São Paulo: Martins Fontes, 2005.

CARUSO, Marina; LIMA, Camila. Prazer, Sabrina. In: Revista Marie Claire, setembro de 2011, n 246. São Paulo: Editora Globo, 2011. p. 79-83.

FREIRE FILHO, João (org). Ser feliz hoje: reflexões sobre o imperativo da felicidade. Rio de Janeiro: Editora FGV, 2010. [referência não encontrada no texto; favor checar]

GOFFMAN, Erving. L’Arrangement entre des sexes. Paris: La Dispute, 2009.

HOUAISS, Antônio e VILLAR, Mauro de Salles. Dicionário Houaiss da língua portuguesa. Rio de Janeiro: Objetiva, 2001.

KELLNER, Douglas. Madonna, moda e imagem. In: . A cultura da mídia. São Paulo: EDUSC, 2001.

KRISTEVA, Julia. Étrangers à nous-mêmes. Paris: Fayard, 1988.

LÉVI-STRAUSS, Claude. Introdução à obra de Marcel Mauss. In: MAUSS, M. Sociologia e antropologia. São Paulo: Cosac Naify, 2003, p. 11-46. 
MCROBBIE, Nagela. Post-Feminism and Popular Culture. In: Feminist Media Studies, vol. 4, $n^{\circ}$ 3. Londres: Taylor \& Francis, 2004, p. 255-264. (a)

Notes on 'What Not To Wear' and post-feminist symbolic violence. In: The Sociological Review, vol. 52, issue supplement s2. Oxford, Malden: Blackwell Publishing, 2004, p. 99-109. (b)

MOI, Toril. Sexual/Textual Politics. Feminist Literary Theory. Londres: Routldge, 1985.

PERROT, Michelle; THÉBAUD, Françoise. (orgs.). História das mulheres no Ocidente. Volume 5. O século XX. Porto: Edições Afrontamento, 1991. [referência não encontrada no texto; favor checar]

SOUZA, Jessé. Os batalhadores brasileiros: nova classe media ou nova classe trabalhadora? Belo Horizonte: Editora UFMG, 2010.

THÉBAUD, Françoise. A Grande Guerra. O triunfo da divisão sexual. In: DUBY, Georges; PERROT, Michelle; THÉBAUD, Françoise (orgs.). História das mulheres no Ocidente. Volume 5. O século XX. Porto: Edições Afrontamento, 1991.

VEBLEN, Thorstein B. A teoria da classe ociosa: um estudo econômico das instituições. São Paulo: Livraria Pioneira Editora, 1965.

Referências primárias citadas

YOUTUBE. 1/5 - Esquadrão da Moda - Melissa - 07/04/2010. Disponível em: <http://www.youtube.com/watch?v=4KhhTMSPE3A>

YOUTUBE. 2/5 - Esquadrão da Moda - Melissa - 07/04/2010. Disponível em: <http://www.youtube.com/watch?v=_QUWzyo-FgQ\&feature=related >

YOUTUBE. 3/5 - Esquadrão da Moda - Melissa - 07/04/2010. Disponível em: <http://www.youtube.com/watch?v=tvyTX_W8-kw\&feature=related $>$

YOUTUBE. 4/5 - Esquadrão da Moda - Melissa - 07/04/2010. Disponível em: <http://www.youtube.com/watch?v=zRYZ2BSs5CY\&feature=related >

YOUTUBE. 5/5 - Esquadrão da Moda - Melissa - 07/04/2010. Disponível em: $<$ http://www.youtube.com/watch?v=Sg_-X_WsoUg\&feature=related $>$

YOUTUBE. 1/4 - Esquadrão da Moda - Thabata Alves - 05/10/2010. Disponível em: $\langle$ http://www.youtube.com/watch?v=L1Na50GrGjc > 
YOUTUBE. 2/4 - Esquadrão da Moda - Thabata Alves - 05/10/2010. Disponível em: <http://www.youtube.com/watch?v=YDTy-lduBZI\&feature=related >

YOUTUBE. 3/4 - Esquadrão da Moda - Thabata Alves - 05/10/2010. Disponível em: $<$ http://www.youtube.com/watch?v=ehK0Q5yCuXM\&feature=related>

YOUTUBE. 4/4 - Esquadrão da Moda - Thabata Alves - 05/10/2010. Disponível em: $<\mathrm{http}: / / \mathrm{www}$.youtube.com/watch?v=0R4Ze7CrGCQ\&feature=related> 